\title{
Recurrent insulinoma syndrome with metastatic glucagonoma
}

\author{
PJS DUNN*, MC SHEPPARD $\dagger$, DA HEATH†, G SLANEY \\ From the Departments of *Pathology, †Medicine and $\ddagger$ Surgery, University of Birmingham, Queen Elizabeth \\ Hospital, Birmingham B15 2TH
}

SUMMARY A case is reported of a patient who presented with symptomatic hypoglycaemia and who had three pancreatic tumours resected over the ensuing eight years. Immunocytochemistry demonstrated two of these to be insulinomas and the third to be a glucagonoma. In addition metastatic spread of cells positive for glucagon had occurred to a lymph node and multiple nodules staining positively for glucagon were present in the remainder of the pancreas.

Pancreatic endocrine tumours are uncommon but of great interest because of the variety of clinical syndromes which they produce. Sensitive immunocytochemical studies have shown that many of these tumours are composed of several cell types and are multihormonal. ${ }^{4} 510$

Transformation from one syndrome to another has been reported ${ }^{9}$ and presumed to be due to change in type of the dominant cell in a mixed tumour. We report a case of recurrent insulinoma syndrome with metastatic glucagonoma, shown by immunocytochemistry to be due to the coexistence of insulinoma and glucagonoma. The importance of immunocytochemistry in accurately defining the nature of these tumours is emphasised.

\section{Case report}

A 24-year-old caucasian man (date of birth 7.8.58) presented in June 1974 with a grand mal convulsion, hypoglycaemia and inappropriately raised serum insulin concentrations (corresponding glucose and insulin values were $1.7,2.3,1.7,1.7 \mathrm{mmol} / \mathrm{l}$ and 39 , $38,32,20 \mathrm{mU} / 1$ respectively). In addition mild hypercalcaemia was noted $(2.88 \mathrm{mmol} / \mathrm{l})$ which was unresponsive to hydrocortisone administration. Raised parathyroid hormone (PTH) concentrations were subsequently documented and his father was noted to have mild hypercalcaemia with high PTH concentrations, suggesting a multiple endocrine adenopathy syndrome, type I. At laparotomy in August 1974 a tumour in the tail of the pancreas was removed. His postoperative course was complicated

Accepted for publication 27 April 1983 by a pancreatic pseudocyst but he remained normoglycaemic, even after a 24-hour fast.

After six asymptomatic years without treatment he again presented with hypoglycaemia and inap- $\underset{\mathbb{\Phi}}{\mathscr{D}}$ propriately raised serum insulin concentrations (glu- $\overrightarrow{ }$ cose $2.9,1.5 \mathrm{mmol} / \mathrm{l}$, insulin $35,38 \mathrm{mU} / \mathrm{l})$. He w treated with diazoxide $100 \mathrm{mg}$ tds. Transhepats portal vein sampling revealed a large "step-up" 亩 serum insulin at the level of the head of pancreas. At surgery (1981) a $2.5 \mathrm{~cm}$ tumour was removed from the head of the pancreas. Immediately postoperatively his blood glucose rose to within the normal range but on the second postoperative day it $\overrightarrow{\overrightarrow{0}}$ returned to the preoperative concentration and he $\frac{0}{3}$ subsequently required continued diazoxide treatment. Repeat transhepatic portal vein sampling confirmed persistently high insulin concentrations in veins draining the head of pancreas and selective arteriography demonstrated a tumour in the head.

Further surgery (1982) was undertaken and another tumour was identified in the head of pancreas adjacent to the superior mesenteric vein. A pancreatico-duodenectomy was performed. Postoperatively the patient has remained asymptomatic and normoglycaemic with no treatment.

\section{Material and methods}

Multiple sections of formalin-fixed paraffinembedded tissue from all three surgical specimens were examined using haematoxylin and eosin, aldehyde fuchsin, congo red and lead haematoxylin stains and by the Grimelius silver impregnation technique. ${ }^{1}$ In addition serial sections from the same blocks were examined by means of the PAP method 1076 


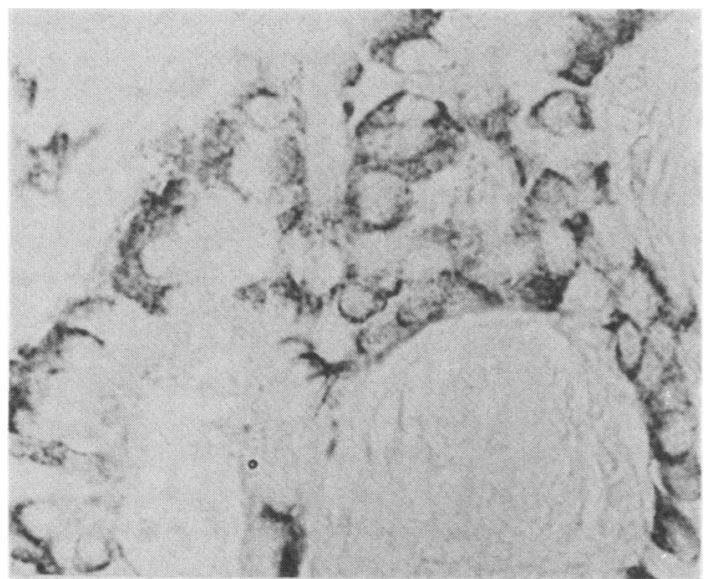

Fig. 1 Tumour removed from tail of pancreas in 1974. Immunocytochemical demonstration of insulin in the majority of tumour cells. Unlabelled antibody-enzyme method using guinea-pig anti-insulin antiserum as first layer. $\times 575$.

of Sternberger et al, ${ }^{2}$ after treatment with trypsin, ${ }^{3}$ using antisera to insulin, glucagon, and somatostatin. The antisera were used at the following dilutions: guinea pig anti-insulin (Immuno-nuclear Corp., PO Box 285, Stillwater, Minnesota, USA) 1/500; rabbit antiglucagon (Mercia Brocades, Brocades House, Pyrford Road, West Byfleet, Surrey) $1 / 500$; rabbit antisomatostatin (Immunonuclear Corp., PO Box 285, Stillwater, Minnesota, USA) $1 / 800$. The second and third stages were performed using sheep antirabbit (RIA UK, 3 Manor Place, Athenaeum Street, Sunderland) and rabbit PAP complex (Mercia Brocades). Appropriate controls were performed, using the specific antibodies after prior absorption with an excess of the corresponding antigen as a first layer, non-immune serum as first layer, and by omission of 3,3'diaminobenzidine tetrahydrochloride from the incubation medium for the peroxidase reaction.

\section{PATHOLOGICAL FINDINGS}

The findings are described separately for the three tumours, identified by the year of removal.

\section{4}

This was a $2 \mathrm{~cm}$ diameter ovoid mass with no attached pancreatic tissue. Microscopy showed a cellular tumour composed of irregular sheets and broad trabeculae of cuboidal basophilic cells with large uniform open nuclei. Occasional mitotic figures were observed. The cells were arranged around a rich sinusoidal vascular network and a thin fibrous capsule was present. Many cells showed silverpositive granules by the Grimelius technique but

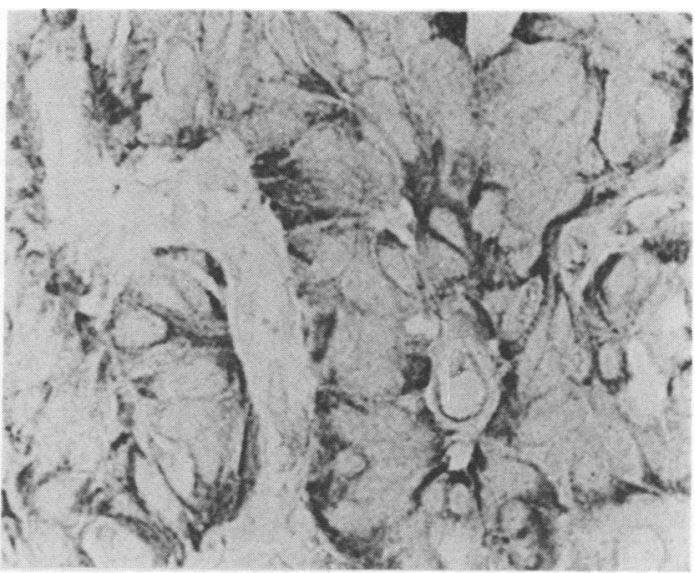

Fig. 2 Tumour removed from head of pancreas in 1981. Immunocytochemical demonstration of glucagon in the majority of tumour cells. Unlabelled antibody-enzyme method using rabbit antiglucagon antiserum as first layer. $\times 575$.

were unstained by aldehyde fuchsin or lead haematoxylin. No amyloid was demonstrable. Immunocytochemistry showed the majority of cells to contain insulin-positive granules (Fig. 1) with occasional cells staining for somatostatin. The two cell types appeared distinct in serial sections examined. No positive staining for glucagon was observed in any of the sections examined. A few cells failed to react with any of the antisera used.

\section{1}

The second tumour removed was a cystic mass $2 \mathrm{~cm}$ $\times 2 \mathrm{~cm} \times 1.5 \mathrm{~cm}$ containing straw-coloured fluid. A small amount of exocrine pancreatic tissue was attached at one pole. Microscopy showed similar cells to the first tumour arranged in a gyriform pattern around numerous blood vessels. A thin capsule of hyaline collagen was present, with areas of infiltration by tumour. Mitoses were not seen. Routine histological staining reactions were identical to the 1974 tumour but the immunohistochemical reactions were quite distinct. No positive staining was obtained with anti-insulin or antisomatostatin, but almost all the tumour cells showed moderate to strong staining with antiglucagon (Fig. 2).

\section{2}

This specimen consisted of pylorus, duodenum, and the head of the pancreas. Within the head of the pancreas and extending to the anterior border there was a firm congested clearly defined nodule $2 \mathrm{~cm}$ diameter. The pancreatic tissue was otherwise unremarkable macroscopically. Several small peripancreatic lymph nodes were identified. Micros- 


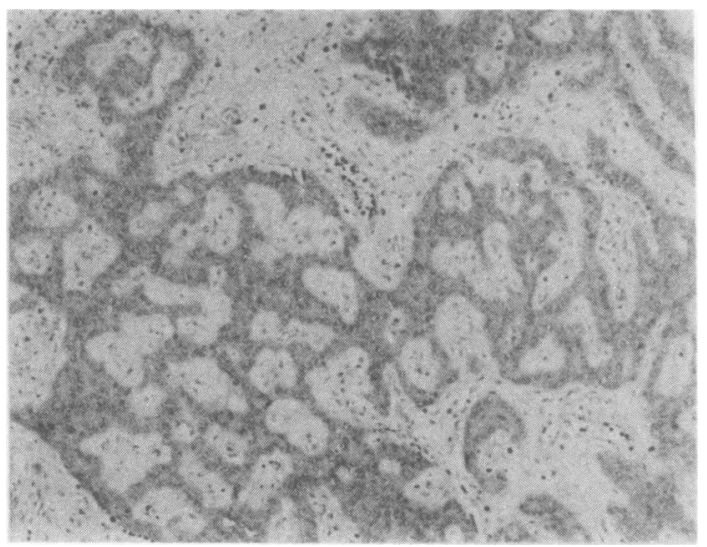

Fig. 3 Main tumour removed with head of pancreas in 1982 showing gyriform pattern. Haematoxylin and eosin. $\times 92$.

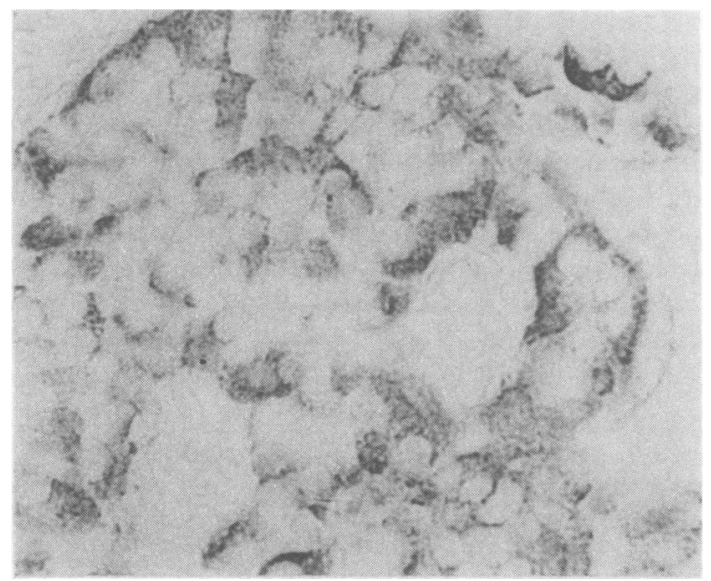

Fig. 4 Main tumour removed with head of pancreas in 1982. Immunocytochemical demonstration of insulin in the majority of the tumour cells. Unlabelled antibody-enzyme method using guinea-pig anti-insulin antiserum as first layer. $\times 575$.

copy of the tumour showed identical appearances to the previous specimen apart from the absence of a clearly defined capsule (Fig. 3). Silver-positive granules were again demonstrable and aldehyde fuchsin and lead haematoxylin were negative. Immunocytochemistry showed the majority of cells to contain insulin (Fig. 4) with a few staining positively for somatostatin. No glucagon-containing cells could be identified in multiple sections examined.

Examination of tissue from elsewhere in the excised pancreas revealed six discrete irregular endocrine cell nodules varying in size from $0.1 \mathrm{~cm}$ to $0.5 \mathrm{~cm}$. The cellular morphology of all six was iden-

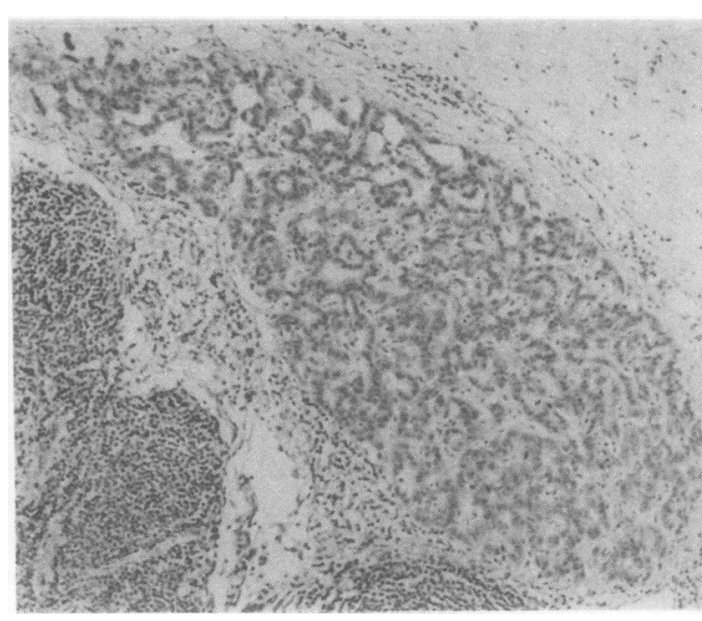

Fig. 5 Metastatic deposit in peripancreatic lymph node removed with head of pancreas in 1982. Haematoxylin and? eosin. $\times 92$.

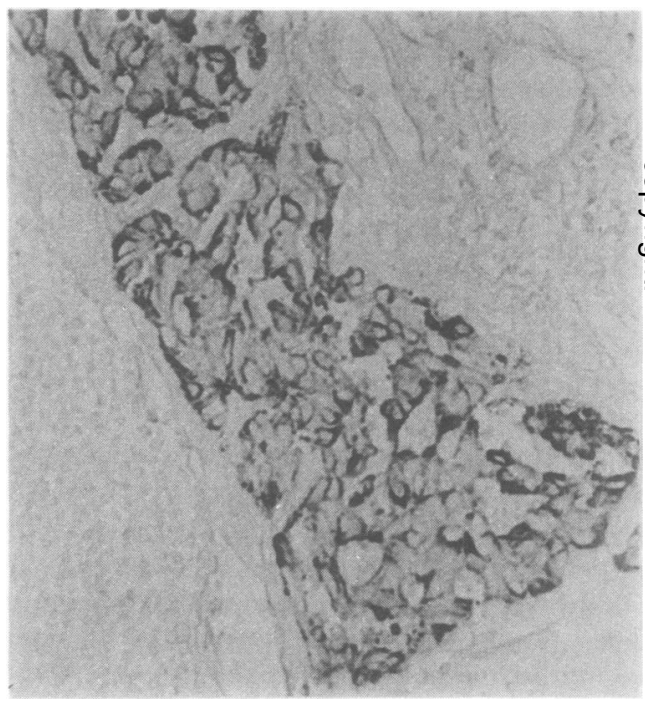

Fig. 6 Metastatic deposit in peripancreatic lymph node

removed with head of pancreas in 1982 . the tumour cells. Unlabelled antibody-enzyme method using rabbit antiglucagon as first layer. $\times 230$. tical to the main tumour. Three of the six werên encapsulated. A further area of tumour was identified within the subcapsular sinus of a peripan $\omega$ creatic lymph node (Fig. 5). All six nodules and the lymph node metastasis were strongly positive foce glucagon (Fig. 6) and negative for both insulin and somatostatin.

The pancreatic islets in the intervening pancreas were irregular in outline and many were hyperplas $\frac{\overrightarrow{\mathbb{D}}}{\mathrm{D}}$ 


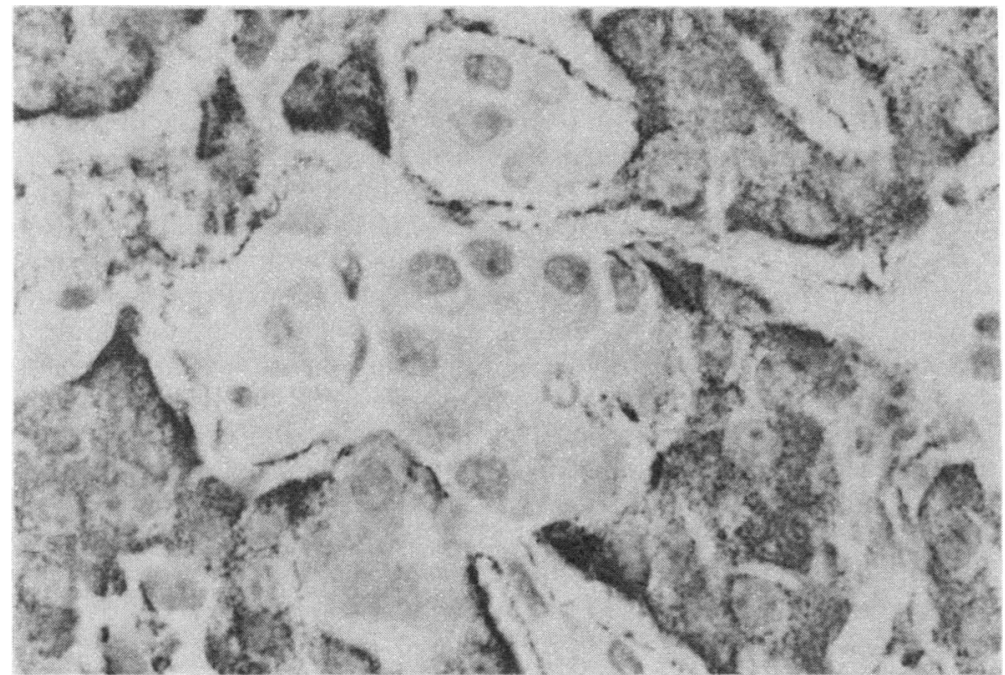

Fig. 7 Edge of main tumour removed with head of pancreas in 1982 showing silver-reactive cells. Unstained cells at centre are exocrine pancreatic tissue. Silver impregnation after Grimelius. $\times 600$.

tic with diameters up to $450 \mu \mathrm{m}$. Columns of endocrine cells appeared to infiltrate between the exocrine cells. Within these large irregular islets the normal arrangement of central B cells and peripheral A and D cells was preserved. Clusters of endocrine cells were also seen in close apposition to small ductules. These clusters contained all three cell types apparently randomly arranged. The exocrine pancreatic tissue was unremarkable.

\section{Discussion}

The accepted classification of pancreatic endocrine tumours has been complicated by the demonstration of the mixed nature of many of these neoplasms. ${ }^{410}$ It has been suggested that the name given to an individual tumour should depend on an appreciation of the clinical, biochemical, and immunocytochemical features of the case..$^{5}$ However, it would seem worth retaining the terms insulinoma, glucagonoma, etc., in view of the recorded differences in biological behaviour. ${ }^{4}$

This case is presented as one of recurrent insulinoma syndrome complicated by the unexpected discovery of metastatic glucagonoma. Recurrent or multiple insulinomas ${ }^{6}$ are rare and most are associated with one of the multiple endocrine neoplasia syndromes. ${ }^{5}$ Malignancy as shown by metastasis, probably the only reliable criterion, is also a rare complication of insulinoma, approximately $5 \%$ in two large series. ${ }^{64}$ In contrast glucagonoma is much more often malignant, in more than $80 \%$ of cases in one series. ${ }^{5}$

The first tumour removed from this patient fulfilled the clinical and immunocytochemical criteria for diagnosis of insulinoma and its removal was followed by a long period of remission. The second tumour, although accompanied by a clinical insulinoma syndrome, showed marked positive staining for glucagon and was entirely negative for insulin. Resection was not accompanied by relief of symptoms and it would seem reasonable to regard this as a glucagonoma. The symptoms of excess glucagon secretion were probably masked by the presence of a further small insulinoma not detected at that time. This insulinoma presumably grew and constituted the main tumour removed at the time of pancreaticoduodenectomy. This third operation was again accompanied by relief of symptoms and the tumour showed positive staining for insulin and was negative for glucagon, and could therefore be confidently labelled an insulinoma. The metastasis found in a lymph node, staining strongly for glucagon only, was presumably metastatic from the glucagonoma previously removed and might be interpreted as evidence of the usual malignant behaviour of glucagonomas.

Despite the heterogeneity revealed by immunohistochemistry, all the tumour tissue examined showed identical staining reactions using conventional techniques. Aldehyde fuchsin is a recognised stain for B cells but no positive staining was obtained with the tumour tissue removed in 1974 or 1982. Others have reported aldehyde-fuchsin positive staining of insulinomas in only about threequarters of the cases examined, ${ }^{8}$ possibly because less insulin is stored in the tumour cells as compared with normal B cells. Likewise, the Grimelius silver impregnation technique specifically demonstrates the A and PP cells of the normal pancreas. However 
Creutzfeldt ${ }^{5}$ reports Grimelius-positive granules in $40 \%$ of 50 insulinomas investigated and quotes another series in which four of 11 insulin producing tumours were positive. In this case argyrophilic granules were present in all three primary tumours (Fig. 7).

Although none of the usual features of hyperglucagonaemia was seen in this case, ${ }^{7}$ future glucagonoma symptoms might be anticipated in view of the likelihood of recurrent disease due to metastatic glucagon-producing tumour. The value of immunocytochemical studies is emphasised in this case as an indication of future behaviour and a guide to which serum hormone concentrations should be monitored for evidence of recurrence. The transformation of a case of insulinoma syndrome into a glucagonoma syndrome has been previously reported by Ohneda et al. ${ }^{9}$ This case appeared to be due to an alteration in the predominant cell type in a mixed endocrine cell tumour. Our case appears to be one of coexistence of two functionally distinct tumours with different biological behaviours.

The relation between insulinoma and glucagonoma is obscure in view of the occurrence of mixed tumours. In this case the two tumour types appear to be distinct. One possibility is that prolonged hyperinsulinaemia induced a secondary A cell hyperplasia leading to neoplasia. However there is no evidence of hyperplasia of A cells alone and the multiple small glucagon-producing tumours in this case are probably metastatic. In view of the postulated origin of pancreatic endocrine tumours from multipotent stem cells in the ductular epithelium rather than from the islets, ${ }^{10}$ it would seem more likely that these tumours are different expressions of an increased tendency to endocrine cell neoplasia. The usual mixed nature of these tumours supports this view. The presence of islet hyperplasia and nesidioblastosis might be regarded as further evidence of a tendency towards endocrine cell proliferation, although others have regarded these features as being due to the tumours. ${ }^{11}$

This report again illustrates the difficulty in classifying these tumours without immunocytochemistry. Indeed this case had been regarded as one of malignant insulinoma before these studies were per- formed and a possibly misleading concept of the likely future symptomatology had been postulated.

In addition to the above studies immunocytochemical staining of the tissue specimens was performed in the Department of Histochemistry, Royal Postgraduate Medical School. These examinations also confirmed positive staining for insulin in the tumour from 1974, glucagon in the tumour from 1981 and insulin in the tumour from 1982 . We are very grateful to Dr Julia M Polak for performing these investigations. We are also grateful to Professor $\mathrm{LH}$ Blumgart and Dr DJ Allison of the Royal Postgraduate Medical School for their help in managing the patient. We wish to thank Mr J Gregory for skilled technical assistance and Miss A Wright for typing the manuscript. MCS is in receipt of a Wellcome Trust Senior Lectureship.

\section{References}

' Grimelius L. A Silver nitrate stain for alpha 2 cells in human pancreatic islets. Acta Soc Med upsal 1968;73:243-70.

${ }^{2}$ Sternberger LA. Immunocytochemistry 2nd ed New York: John Wiley \& Sons, 1979.

${ }^{3}$ Curran RC, Gregory $J$. The unmasking of antigens in paraffin sections of tissue by trypsin. Experientia 1977;33:1400-1.

${ }^{4}$ Heitz PU, Kasper M, Polak J, Kloppel G. Pancreatic endocrine tumours. Hum Pathol 1982;13:263-71.

${ }^{5}$ Creutzfeldt W. Endocrine tumours of the pancreas. In: Volk B Wellman KF, eds. The diabetic pancreas. London: Ballière Tindall, 1977:551-90.

- Service JF, Dale AJD, Elveback RL, Jiang NS. Insulinoma, clinical and diagnostic features of 60 consecutive cases. Mayo Clin Proc 1976;51:417-29.

' Matheson LN, Bloom SR, Warin AP, Salmon PR, Cox BA. A glucagonoma syndrome. Lancet 1974;ii:1-5.

${ }^{8}$ Creutzfeldt W. Endocrine tumours of the pancreas. Monogr Pathol 1980;21:208-30.

' Ohneda A, Otsuki M, Fujiya H, Yaginuma N, Kokubo T, Ohtari H. A malignant insulinoma transformed into a glucagonoma syndrome. Diabetes 1979;28:962-9.

${ }^{10}$ Larsson LI. Endocrine pancreatic tumours. Hum Pathol 1978;9:401-15.

"Larsson LI. Two distinct types of islet abnormality associated with endocrine pancreatic tumours. Virchows Arch [Pathol Anat ] 1977;376:209-19.

Requests for reprints to: Dr PJS Dunn, Department of 옥 Pathology, The Medical School, Birmingham B15 2TJ, I England. 